\title{
Increased Private Healthcare for Canada: Is That the Right Solution?
}

\section{Accroître les services de santé privés au Canada : est-ce la bonne solution?}

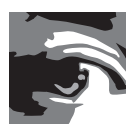 \\ SHOO K. LEE, MBBS, FRCPC, PhD, DHC, OC \\ Professor of Paediatrics, Obstetrics E Gynecology, and Public Health \\ University of Toronto \\ Director \\ Maternal-Infant Care (MiCare) Research Centre \\ Mount Sinai Hospital \\ Toronto, ON \\ BRIAN H, ROWE, MD, MSC, CCFP (EM), FCFP, FCCP, FCAHS \\ Professor \\ Department of Emergency Medicine and School of Public Health \\ University of Alberta \\ Edmonton, $A B$ \\ SUKHY K. MAHL, MBA \\ Assistant Director \\ Maternal-Infant Care (MiCare) Research Centre \\ Mount Sinai Hospital \\ Toronto, ON
}

\begin{abstract}
Medicare is a publicly funded healthcare system that is a source of national pride in Canada; however, Canadians are increasingly concerned about its performance and sustainability. One proposed solution is private financing (including both private for-profit insurance and private out-of-pocket financing) that would fundamentally change medicare. We investigate international experiences to determine if associations exist between the degree of private spending and two of the core values of medicare - universality and accessibility - as well as the values of equity and quality. We further investigate the impact of private spending on overall health system performance, health outcomes and health expenditure growth rates. Private financing (both private for-profit insurance and private out-of-pocket financing) was
\end{abstract}


found to negatively affect universality, equity, accessibility and quality of care. Increased private financing was not associated with improved health outcomes, nor did it reduce health expenditure growth. Therefore, increased private financing is not the panacea proposed for improving quality or sustainability. The debate over the future of medicare should not be rooted in the source of its funding but rather in the values Canadians deem essential for their healthcare system.

\section{Résumé}

L'assurance maladie, un système de santé financé par l'État, est source de fierté nationale au Canada. Cependant, les Canadiens sont de plus en plus préoccupés par son rendement et sa durabilité. Une solution proposée est le financement privé (notamment l'assurance privée à but lucratif et le financement direct privé), ce qui changerait fondamentalement le régime d'assurance maladie. Nous avons étudié la situation à l'étranger pour déterminer s'il existe une association entre le degré de dépenses privées et deux valeurs fondamentales de l'assurance maladie : l'universalité et l'accessibilité. Nous avons examiné plus en détail l'impact des dépenses privées sur la performance générale du système de santé, sur les résultats cliniques et sur le taux de croissance des dépenses de santé. Nous avons constaté que le financement privé (l'assurance privée à but lucratif et le financement privé direct) avait un effet négatif sur l'universalité, l'équité, l'accessibilité et la qualité des soins. Laugmentation du financement privé n'est pas associé à de meilleurs résultats cliniques, ni à un ralentissement de la croissance des dépenses de santé. Par conséquent, l'augmentation du financement privé n'est pas la panacée pour une amélioration en matière de qualité ou de durabilité. Le débat sur l'avenir de l'assurance maladie ne devrait pas s'enraciner dans la source de son financement, mais plutôt dans les valeurs que les Canadiens jugent essentielles pour leur système de santé.

\section{Medicare's Challenges and the Call for Private Financing}

Medicare - the publicly funded, single-payer network of healthcare systems - is a popular Canadian public program, which is a source of national identity and great pride (CIHI 2017; Martin et al. 2018; Simpson 2012). Since medicare's initial introduction covering in-hospital and diagnostic services in 1957, through to the enactment of the Canada Health Act (CHA) (Government of Canada 1985) in 1985, the principles have included universality, portability, comprehensiveness and public administration. The enactment of the CHA also added accessibility as the fifth principle of medicare. Operationally, this includes no direct cost to patients for medically necessary hospital and physician services. Despite these achievements, Canadians are increasingly concerned about the system's performance (Martin et al. 2018; Simpson 2012). For example, long wait times for elective surgical procedures such as joint replacements, cataract surgeries and cardiac procedures; overcrowded emergency departments; and lack of access to primary care providers have all become fodder for news highlights and calls for change (Maclean's 2013). Moreover, among the Organisation for Economic Co-operation and Development (OECD) countries, Canada ranks average on 
healthcare performance despite spending more per capita than most other countries (CIHI 2017). The OECD rankings from 1960 to 2010 compare 17 high-income countries on five dimensions of health: health status, non-medical determinants of health, quality of care, patient safety and access to care. One commentator has described Canada's healthcare as "a Chevrolet system at Cadillac prices" (Simpson 2012). Even more worrisome is that Canada's healthcare performance ranking continues to slip in the Commonwealth Fund comparison of 11 high-income countries, starting at fourth place in 2004, slipping to fifth in 2006, sixth in 2010 and ninth in 2017. Closer examination reveals that Canada's mediocre rankings in the majority of international healthcare indices are predominantly a result of long wait times for elective care and inequitable access to services outside the core medicare coverage of hospital, physician and diagnostic services (Martin et al. 2018). Wait times plague the system, with $18 \%$ of Canadians waiting more than four months for elective non-urgent surgery and $30 \%$ waiting more than two months for specialist referrals (Martin et al. 2018).

There is no shortage of proposed solutions, from increasing funding to expanding scope of care for nonphysician healthcare providers. Some have called for increased private financing of Canada's healthcare system through either out-of-pocket payments or private health insurance. Still others have proposed diverting more services to for-profit clinics that, they argue, will lower overall surgical wait times by reducing the workload on publicly funded facilities. However, critics contend that this will only reduce wait times for those able to afford the private services - for everyone else, wait times may actually increase as healthcare providers may divide their time between publicly and privately financed services but spend less time in the publicly financed side.

A major constitutional challenge in British Columbia (BC) alleges that the restrictive $\mathrm{CHA}$ and provincial legislation infringe on patients' rights to life, liberty and security of the person under the Canadian Charter of Rights and Freedoms (Flood and Thomas 2018). The arguments before the BC Supreme Court asserted that patients should have the right to obtain medical services more quickly by paying privately, and physicians should be allowed to "extra bill" patients for these services in the public system while also being permitted to "dual practice," working both in the public and an exclusively privately funded system. Extra billing is defined as charging an additional amount for an insured service to an insured person above and beyond the rate paid by the insurance plan of the province. Advocates of private financing range from governments to citizens, based on differing motivations. Governments may welcome more private financing to reduce taxes or to allocate funds elsewhere, whereas some citizens may advocate for private financing in order to reduce their tax burdens and improve their own access to healthcare services, and some physicians may be motivated by personal financial gain. Others claim that increased private financing will free public funds to improve access for patients in the public system, but critics argue that it will instead reduce access by undermining support for public financing. Although the BC Supreme Court recently ruled to uphold the BC Medicare Protection Act (Government of British Columbia 1996), it is possible that the plaintiffs may move to have the case heard by the Supreme Court of Canada, 
and the outcome may have the potential to impact healthcare delivery in Canada.

Canada's healthcare system is unique in that guaranteed access to core physician and hospital services is provided, while other important areas of healthcare are left open to ad hoc public coverage, which varies between provinces (CIHI 2018). Despite this, many Canadians perceive Canada's healthcare system as overwhelmingly publicly funded. In reality, Canada is considered "middle of the road" among OECD nations, with a 70\%:30\% public-private split of healthcare expenditures, slightly below the OECD average (73\% public and $27 \%$ private; CIHI 2018). Even though US healthcare is often considered private, it is $48 \%$ publicly funded, 52\% private, and the public share is rising (CMS 2018; WHO 2020). In contrast, Canadian public sector spending declined from $76 \%$ to $70 \%$ over the past 40 years (CIHI 2018). In some provinces, the decline was even steeper. For example, Ontario's public sector health share fell from $75 \%$ to $66 \%$ (CIHI 2018).

The framing of the healthcare financing debate in Canada is unfortunate because it equates sustainability and quality with public or private financing. A better alternative is to discuss healthcare financing in the context of the values that Canadians want to see in their healthcare system. In a free market equilibrium, demand and supply balance each other; however, healthcare is not a typical market good. In a free healthcare market, wealthier people would have the ability to access more and expedited healthcare, whereas poor people would make do with less and wait longer. During the Great Depression of the early 1930s (Struthers 2020), many people lacked the means to purchase even basic healthcare, and social conscience led Canada's leaders to make healthcare a public instead of a private good by introducing elements of universal health insurance and eventually creating the CHA. The CHA embodies the core values of universality, comprehensiveness, portability, public administration and accessibility (Health Canada 2015). A public good is one that is open for all to use, and consumption by one party does not deter another party's ability to use it; however, if demand outstrips supply, as is the case in healthcare, this can lead to market failure. Regulation or public policy can work to alleviate market failure. Canada's medicare relies on supply-side control where supply (e.g., physicians, surgical suites and hospital beds) is limited, while demand is not. Some contend that supply control without demand control is unsustainable, and when demand exceeds supply, implicit rationing results in long wait times and compromises access to and quality of care. All OECD countries, except Canada and the UK, use some form of copayment or user fees for physician and hospital care to control demand (Institute for Competitiveness \& Prosperity 2014). Some countries also allow for the purchase of private insurance to cover the copayments - as is done in France. However, opponents are concerned that this disadvantages some groups (lower income groups, extremes of age, immigrants, etc.), instead, arguing that better efficiency and resource allocation should suffice (Ontario Ministry of Finance 2012). Others propose increased private financing to fill the supply "shortfall" (Kaczorowski 2010); critics argue that because only the wealthy can afford private healthcare, this will create a two-tiered healthcare system that compromises medicare's core values (Flood and Choudhry 2002) and could undermine 
public support for medicare. Moreover, evidence suggests that access (e.g., wait times) will not improve if a two-tiered system is adopted (Duckett 2005). Here, we examine the experiences of other countries, via health indices, to explore how increased private financing may impact widely accepted values in our healthcare system, overall health system performance, health outcomes and growth in health expenditures. Our analysis of private financing includes both private for-profit insurance and private out-of-pocket financing. Discussion of private services refers to those provided in both private for-profit and private not-for-profit modalities.

\section{The Impact of Privatization}

\section{Methods}

We analyzed the potential impact of increased private financing in Canadian healthcare by searching for and examining published health indices for associations between private health-spending share in a country and the country's ranking for two core $\mathrm{CHA}$ principles (universality and accessibility) and two values expressed during the Romanow Commission (equity and quality; Romanow 2002), as well as overall health system performance and health outcomes. The remaining three principles of the CHA (public administration, portability and comprehensiveness) were not selected for analysis as they are not included in international health system rankings. Therefore, universality and accessibility were the two $\mathrm{CHA}$ principles included in the analysis. Health indices analyzed include the Institute for Health Metrics and Evaluation's (IHME) Health-Related Sustainable Development Goals (SDG) Universal Health Coverage Index, the Commonwealth Fund's (CWF) Health Care System Performance Rankings, Economist Intelligence Unit's (EIU) Global Access to Healthcare Index, IHME Healthcare Access and Quality Index (HAQ) and the Bloomberg Global Health Healthiest Country Index (BGH). Data for each nation's private sector health spending were principally drawn from the World Health Organization's (WHO) Key Country Indicators data set (WHO 2020). The impact of increased private financing on health expenditure growth (HEG) was assessed by analyzing HEG rates in a group of highincome countries representing a broad range of private financing within their health systems.

\section{Results}

\section{UNIVERSALITY}

The IHME measured 37 of 50 health-related SDG indicators over the period of 1990 to 2016 for 188 countries (Fullman et al. 2017). We used the IHME SDG Universal Health Coverage Index (that examines childhood vaccination, antenatal care, in-facility delivery rate, antiretroviral therapy and risk-standardized death rates from causes amenable to healthcare) to assess the impact of private financing on universality. Our analysis shows that health systems with more private services were significantly $(p<0.01)$ associated with lower universal health coverage rankings; however, large variations existed across nations. 


\section{EQUITY}

We used the CWF Equity sub-index (that examines timeliness, financial barriers to care and patient-centred care) and the EIU Equity of Access sub-index (that examines access to appropriate health services) to assess the effect of private financing on health equity (EIU 2018; Schneider et al. 2017). Of note is that the CWF Equity sub-index assessed equity overall, whereas the EIU Equity of Access sub-index specifically assessed equity of access. In both the EIU Equity of Access and CWF Equity sub-indices, health systems with more private services were significantly $(p<0.05)$ associated with poorer equity rankings.

\section{ACCESS}

We used the CWF Access sub-index (that evaluates affordability and timeliness) and the EIU Accessibility sub-index (that examines access to child and maternal health services, infectious diseases care, non-communicable diseases care, medicines and equity of access) to assess the impact of private financing on accessibility (EIU 2018; Schneider et al. 2017). In both the EIU Accessibility (Figure 1) and CWF Access sub-indices, health systems with more private services were significantly $(p<0.05)$ associated with poorer accessibility rankings.

FIGURE 1. Lower percentages of private financing are associated with improved accessibility ranking using the EIU Accessibility index

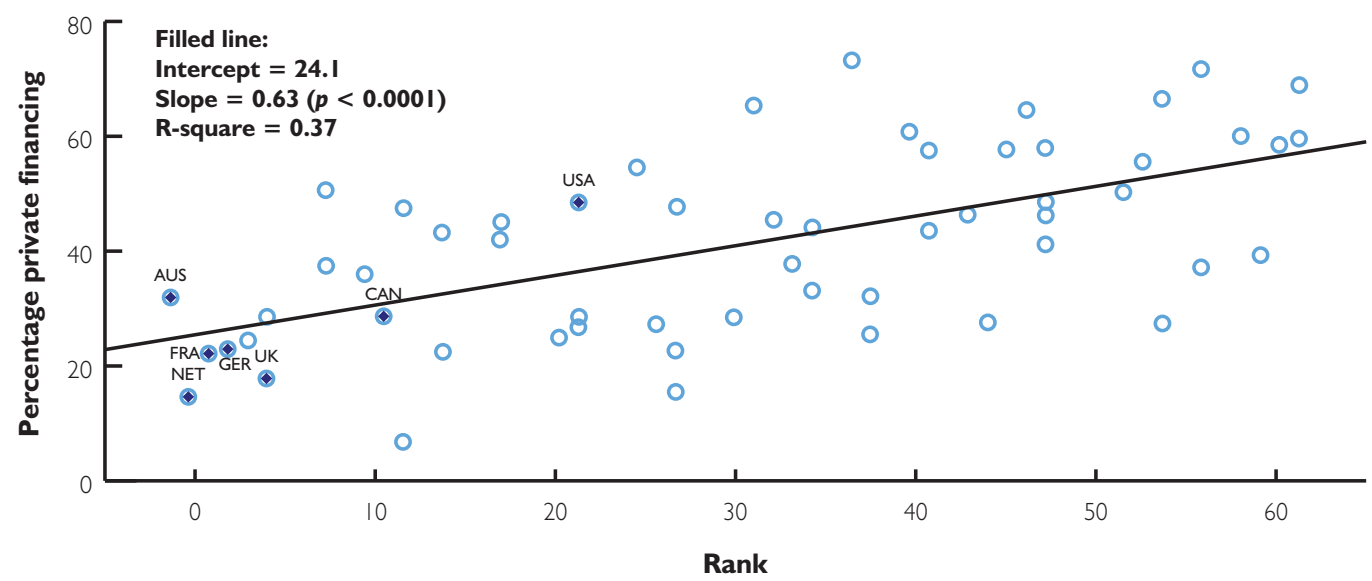

CWF-ranked countries are highlighted. AUS - Australia; CAN - Canada; FRA - France; GER - Germany; NET - Netherlands; NOR - Norway; NWZ - New Zealand; SWE - Sweden; SWI - Switzerland; UK - United Kingdom; USA - United States of America.

QUALITY

We used the IHME HAQ (that is based on risk-standardized mortality rates from causes that, in the presence of high-quality healthcare, should not result in death - also known as amenable mortality) to assess the impact of private financing on access and quality of the healthcare system (Barber et al. 2017). In the HAQ index, health systems with more private services were significantly $(p<0.01)$ associated with poorer access and quality rankings. 
HEALTH SYSTEM PERFORMANCE

We used the CWF Health Care System Performance index (that examines care process performance, access, administrative efficiency, equity and healthcare outcomes) and the EIU Healthcare System sub-index (that examines measures enabling conditions to provide access to healthcare services, including population coverage, political will, healthcare infrastructure and efficiency and innovation mechanisms) to assess the impact of private financing on overall health system performance (EIU 2018; Schneider et al. 2017). In the EIU Healthcare System sub-index, health systems with more private services were significantly $(p<0.01)$ associated with poorer health system performance. In the CWF Health Care System Performance index, health systems with more private services were associated with poorer overall health system performance, but the relationship was not statistically significant.

\section{HEALTH OUTCOMES}

Finally, we used the CWF Health Care Outcomes sub-index (that examines population health factors, mortality amenable to healthcare and disease-specific outcomes) and the BGH (that examines life expectancy, causes of death and health risks) to assess the effect of private financing on health outcomes (Lu and Del Giudice 2017). Using both the BGH and the CWF Health Care Outcomes sub-index (Figure 2), health systems with more private services were not associated with improved health outcomes.

FIGURE 2. Percentage of private financing is not associated with overall health rankings using the CWF Health Care Outcomes sub-index

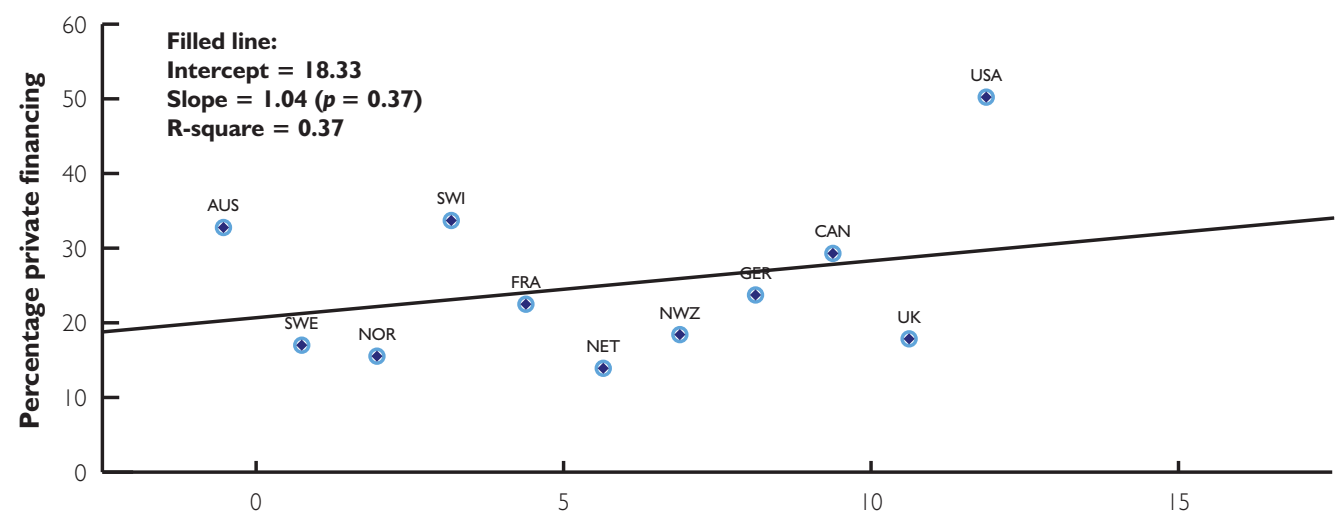

AUS - Australia; CAN - Canada; FRA - France; GER - Germany; NET - Netherlands; NOR - Norway; NWZ - New Zealand; SWE - Sweden; SWI - Switzerland; UK - United Kingdom; USA - United States of America.

\section{HEALTH EXPENDITURE GROWTH}

Our analysis shows that health systems with more private services were not significantly associated with health expenditure growth rates. 


\section{Discussion: The Implications of Privatization}

Our findings provide further evidence that systems with higher rates of private financing are negatively associated with universality, equity, accessibility and quality of care, as has previously been found in international literature reviews (Alkhamis 2017; Bambra et al. 2014; Footman et al. 2014). We did not find an association between private financing and improved health outcomes. Health outcomes may be affected more by socio-economic determinants of health (Dutton et al. 2018) and health behaviours than by how healthcare is financed, or improved outcomes among those who can purchase care may be offset by worse outcomes among those who cannot.

Canada's unique health system lacks comprehensiveness because it covers unlimited demand to a narrow range of services (physicians and hospitals), leaving other important areas of healthcare (e.g., dental care, pharmaceuticals and allied health services) open to ad hoc public or private coverage. This is a concern because lack of comprehensiveness (e.g., physician services without access to outpatient prescription drugs) can diminish effectiveness in the healthcare system. In contrast, many other OECD nations publicly fund access to a broader range of basic healthcare services; however, they control demand by requiring top-up private insurance for added services (Schoen et al. 2010). In these countries, it is considered that universal healthcare does not imply "free at the point of delivery" healthcare, and proponents contend that carefully designed price signals can bring benefits of both cost efficiency and equity (Institute for Competitiveness \& Prosperity 2014). It should be noted, however, that copays deter the poor and extremes of age from accessing care. Moreover, they represent no deterrent to the rich and may reduce both medically unnecessary and medically necessary care, meaning direct patient payment would require a thoughtful and deliberate policy setting (Evans et al. 1995).

If private financing was expanded in Canada, the resulting impact on health system values would depend on the design and regulation of the private system. If it is designed to provide enhanced access and services based on willingness to pay, it will certainly reduce equity. If, on the other hand, regulations that restrict a parallel system based on willingness to pay are introduced, then the core values of medicare may not be at risk, although there is a lack of precedents to provide evidence for this. For the readers' consideration, we have included an adapted summary of the health financing models in Box 1 (CMA Task Force on the PublicPrivate Interface 2006).

Private health insurance can take on different forms - it can duplicate, complement or supplement public health coverage.

BOX 1. An adapted summary of health financing models

\begin{tabular}{|l|l|}
\hline Model & Description \\
\hline Beveridge & $\begin{array}{l}\text { Public health insurance } \\
\text { funded by general } \\
\text { government revenues } \\
\text { (i.e., UK and Canada) }\end{array}$ \\
\hline Bismarck & $\begin{array}{l}\text { Healthcare funded through } \\
\text { premiums or social } \\
\text { insurance contributions } \\
\text { (i.e., Germany and France) }\end{array}$ \\
\hline Pluralistic & $\begin{array}{l}\text { Multiple public and } \\
\text { private payers (i.e., Italy, } \\
\text { japan and the US) }\end{array}$ \\
\hline
\end{tabular}


Duplicate private insurance competes with public health insurance and is common in systems with separation between publicly and privately funded providers. Complementary private insurance provides coverage for out-of-pocket payments that may be required by public systems. Supplementary private insurance covers services not covered by public plans (CMA Task Force on the Public-Private Interface 2006).

Supplementary insurance already exists in Canada, so any further changes to the private financing of healthcare in Canada may include expansion into complementary or duplicate insurance. Clearly, duplicate private insurance can easily lend itself to a "two-tier" system that goes against Canadians' values for medicare, whereas progressive tax policies can mitigate the impact of the cost of complementary or supplementary plans. Additional considerations are whether private insurance companies will be allowed to risk rate or cherry-pick and exclude enrollees, whether they are for-profit or non-profit and whether physicians will be mandated to work a specified number of hours in the public system before they are able to operate in the private system. Consequently, regulations and public policy governing private financing may temper the degree to which medicare values are impacted and will need careful consideration.

Sustainability, or the ability to maintain the healthcare system both fiscally and operationally, is crucial. An infusion of private funds and/or diverting patients to private services may provide temporary relief to wait times by allowing those with the ability to pay privately to "jump the queue" and allowing physicians to work additional hours beyond those already worked in the public system in the private sector; however, supply would eventually become saturated once again, as the number of physicians and physician-working hours are finite, whereas demand is not. The key to sustainability, however, is not private versus public funding models, but rather controlling the annual HEG, also known as health inflation. The reasons for HEG include population growth, aging, inefficiency, labour and drug price inflation and technological change, among others (CIHI 2011). A Canadian Institute for Health Information report indicates that demographic factors such as population growth and aging contribute only modestly to HEG, although that may change as the proportion of the seniors in the population rapidly grows (CIHI 2011). If HEG consistently exceeds the growth rate of the economy, the system is unsustainable irrespective of private or public financing as health costs will increasingly consume available resources and squeeze out other forms of consumption (Dodge and Dion 2011). Although some may argue that healthcare is only as sustainable as we wish it to be, one must acknowledge that we do not have limitless public resources to spend on healthcare, and if HEG continues to exceed the growth rate of the economy, it will either lead to a reduction in spending on other public domains, or continually increase tax burdens. Canada's HEG has exceeded economic growth by an average of $1.3 \%$ annually over the past 40 years (1976-2015; CIHI 2018). Other countries have similar experiences, including the US, where HEG has exceeded economic growth by an average of $2.1 \%$ over the same time frame (CMS 2018). In fact, health spending has grown 
faster than the economy in all OECD countries over the past 20 years (OECD 2015). Our results show no relationship between HEG and private financing in a healthcare system; therefore, increased private financing neither improves nor worsens sustainability of the healthcare system.

A broad consensus among health economists holds that technological change is a primary driver of HEG (Smith et al. 2009). In a study of 23 OECD countries, Smith et al. (2009) reported that technological change accounts for $27 \%$ to $48 \%$ of HEG. Some advocate regulation of technology adoption, while others argue that productivity gains from technological innovation are not reflected in price adjustments (Di Matteo and Emery 2015: 87-112). For example, while technological innovation has dramatically reduced the time needed for cataract surgery, the service fee has not decreased proportionately, and the benefits have been captured by service providers instead of payers. Controlling HEG is central to addressing sustainability.

\section{Limitations}

All health indices and ranking systems are limited by the evaluation factors chosen; there is no consensus on international standards. Using the same evaluation factors for low- and high-income countries may be questioned. Availability and quality of data may vary among countries and bias the results, and there may be a lack of consensus within international rankings; for example, although many international indices rank the Canadian healthcare system as average, the IHME HAQ index ranks it as relatively high. Finally, these results reflect associations, not causation.

\section{Conclusion}

In conclusion, sustainability and quality cannot be equated with public or private financing, and the argument for an expanded role for private financing is a distraction from the key questions that Canadians need to address: What values and principles do Canadians wish to see in their healthcare system? How can national consensus for healthcare reform and sustainability be achieved? Difficult decisions regarding coverage and financing of services and pragmatic choices to sustain the system have to be made. Private financing on its own is not the answer. The responsibility for mobilizing public and political support for healthcare reform should belong to the government but need not rest solely with it and should not be appropriated by self-profiting special interest groups. In this era of social media, community groups can readily mobilize public interest, raise awareness and generate public discussion, leading to public pressure for change. While previous efforts have relied heavily on academic studies, think tank reports and government-commissioned recommendations (e.g., senate and parliamentary committees and royal commissions), engaging the community through town hall meetings and social media, or video streaming of TED-style talks and Munk-style debates, can broaden public engagement and amplify knowledge dissemination. Levers for 
implementing reform can include changes to the $\mathrm{CHA}$, a federal-provincial transfer system and provincial legislations. Real change that fully embraces the values that Canadians want in their healthcare system will only come when there is broad public support for politicians to make difficult policy choices. Canadians have a right to decide the future of medicare.

\section{Acknowledgements}

The authors gratefully acknowledge the staff at the Maternal-Infant Care (MiCare) Research Centre at Mount Sinai Hospital, Toronto, ON, for their support. In addition, we specifically thank MiCare staff Xiang Y. Ye, MSc, for statistical support; Valentina Ly, MLIS, for data collection and research support; and Sarah Hutchinson, $\mathrm{PhD}$, for editorial assistance in the preparation of this manuscript.

\section{Funding statement}

Although no specific funding has been received for this study, organizational support was provided by the MiCare Research Centre at Mount Sinai Hospital. MiCare is supported by the Canadian Institutes of Health Research (CIHR) Team Grant (CTP 87518) and the Ontario Ministry of Health. Dr. Rowe's research is supported by a Scientific Directors Operating Grant (SOP 168483) from CIHR. The funding agencies had no role in the design and conduct of the study; collection, management, analysis and interpretation of the data; preparation, review or approval of the manuscript; and the decision to submit the manuscript for publication.

Correspondence may be directed to: Dr. Shoo K. Lee, Department of Pediatrics, Mount Sinai Hospital, 19-231M, 600 University Avenue, Toronto, ON M5G 1X5. Dr. Lee can be reached by phone at 416-586-4800x6370 or by e-mail at shoo.lee@sinaihealth.ca.

\section{References}

Alkhamis, A.A. 2017. Critical Analysis and Review of the Literature on Healthcare Privatization and Its Association with Access to Medical Care in Saudi Arabia. Journal of Infection and Public Health 10(3): 25868. doi:10.1016/j.jiph.2017.02.014.

Bambra, C., K. Garthwaite and D. Hunter. 2014. All Things Being Equal: Does It Matter for Equity How You Organize and Pay for Health Care? A Review of the International Evidence. International Journal of Health Services 44(3): 457-77. doi:10.2190/HS.44.3.c.

Barber, R.M., N. Fullman, R.J.D. Sorensen, T. Bollyky, M. McKee, E. Nolte et al. 2017. Healthcare Access and Quality Index Based on Mortality from Causes Amenable to Personal Health Care in 195 Countries and Territories, 1990-2015: A Novel Analysis from the Global Burden of Disease Study 2015. The Lancet 390(10091): 231-66. doi:10.1016/S0140-6736(17)30818-8.

Canadian Institute for Health Information (CIHI). 2011, October. Health Care Cost Drivers: The Facts. Retrieved December 10, 2018. <https://secure.cihi.ca/free_products/health_care_cost_drivers_the_ facts_en.pdf>.

Canadian Institute of Health Information (CIHI). 2017, February. International Comparisons at CIHI. Retrieved September 19, 2019. <https://secure.cihi.ca/free_products/international-comparisons-en-web. pdf?_ga $=2.233958109 .292325556 .1568902839-1857376077.1567705026>$. 
Canadian Institute for Health Information (CIHI). 2018. National Health Expenditure Trends, 1975 to 2018. Retrieved December 10, 2018. <https://secure.cihi.ca/free_products/NHEX-trends-narrative-report-2018-enweb.pdf>.

Canadian Medical Association (CMA) Task Force on the Public-Private Interface. 2006. It's About Access! Informing the Debate on Public and Private Health Care. Canadian Medical Association.

Centers for Medicare \& Medicaid Services (CMS). 2018. National Health Expenditure Data - Historical. Retrieved December 10, 2018. <https://www.cms.gov/Research-Statistics-Data-and-Systems/Statistics-Trendsand-Reports/NationalHealthExpendData/NationalHealthAccountsHistorical.html>.

Di Matteo, L. and J.C.H. Emery. 2015. Chapter 4: Common Provincial Determinants and Cost Drivers. In G.P. Marchildon and L. Di Matteo, (eds.). Bending the Cost Curve in Health Care: Canada's Provinces in International Perspective (1st ed.) (pp. 87-112). University of Toronto Press.

Dodge, D.A. and R. Dion. 2011, April. Chronic Healthcare Spending Disease: A Macro Diagnosis and Prognosis. C.D. Howe Institute Commentary: The Health Papers. Retrieved December 10, 2018. <https://www.cdhowe. org/sites/default/files/attachments/research_papers/mixed//Commentary_327.pdf>.

Duckett, S.J. 2005. Private Care and Public Waiting. Australian Health Review 29(1): 87-93. doi:10.1071/ ah050087.

Dutton, D.J., P.-G. Forest, R.D. Kneebone and J.D. Zwicker. 2018. Effect of Provincial Spending on Social Services and Health Care on Health Outcomes in Canada: An Observational Longitudinal Study. Canadian Medical Association Journal 190(3): E66-71. doi:10.1503/cmaj.170132.

Evans, R.G., M.L. Barer and G.L. Stoddart. 1995. User Fees for Health Care: Why a Bad Idea Keeps Coming Back (Or, What's Health Got to Do with It?). Canadian Journal on Aging 14(2): 360-90. doi:10.1017/ S0714980800011880.

Flood, C.M. and S. Choudhry. 2002, August. Strengthening the Foundations: Modernizing the Canada Health Act. Discussion Paper No. 13. Commission on the Future of Health Care in Canada. Retrieved December 10, 2018. <http://publications.gc.ca/collections/Collection/CP32-79-13-2002E.pdf>.

Flood, C.M. and B. Thomas. 2018. A Successful Charter Challenge to Medicare? Policy Options for Canadian Provincial Governments. Health Economics, Policy, and Law 13(3-4): 433-49. doi:10.1017/S1744133117000469.

Footman, K., K. Garthwaite, C. Bambra and M. McKee. 2014. Quality Check: Does It Matter for Quality How You Organize and Pay for Health Care? A Review of the International Evidence. International Journal of Health Services 44(3): 479-505. doi:10.2190/HS.44.3.d.

Fullman, N., R.M. Barber, A.A. Abajobir, K.H. Abate, C. Abbafati, K.M. Abbas et al. 2017. Measuring Progress and Projecting Attainment on the Basis of Past Trends of the Health-Related Sustainable Development Goals in 188 Countries: An Analysis from the Global Burden of Disease Study 2016. The Lancet 390(10100): 1423-59. doi:10.1016/S0140-6736(17)32336-X.

Government of British Columbia. 1996. Medicare Protection Act [RSBC 1996] Chapter 286. Retrieved January 1, 2021. <https://www.bclaws.gov.bc.ca/civix/document/id/complete/statreg/96286_01>.

Government of Canada. 1985. Canada Health Act, R.S.C., 1985, c. C-6. Retrieved January 12, 2021. $<$ http://www.cwhn .ca/en/node/27868>.

Health Canada. 2015. Canada Health Act Annual Report 2014-2015. Retrieved December 10, 2018. <https:// www.canada.ca/content/dam/hc-sc/migration/hc-sc/hcs-sss/alt_formats/pdf/pubs/cha-ics/2015-cha-lcs-ar-raeng.pdf $>$.

Institute for Competitiveness \& Prosperity. 2014. Building Better Health Care: Policy Opportunities for Ontario. Working Paper 20. Retrieved December 10, 2018. <https://www.competeprosper.ca/uploads/WP20_ BetterHealthCare_FINAL.pdf $>$.

Kaczorowski, J. 2010. Who Still Has the Worst Health System of Them All? The Lancet 376(9747): 1146. doi:10.1016/S0140-6736(10)61038-0.

Lu, W. and V. Del Giudice. 2017, March 20. Italy's Struggling Economy Has World's Healthiest People. Bloomberg. Retrieved December 10, 2018. <https://www.bloomberg.com/news/articles/2017-03-20/ italy-s-struggling-economy-has-world-s-healthiest-people>. 
Maclean's. 2013, February 19. When It Comes to Waiting for Health Care, Canada Is Last in Line. Maclean's. Retrieved September 25, 2019. <https://www.macleans.ca/politics/when-it-comes-to-waiting-canada-is-lastin-line-2/>.

Martin, D., A.P. Miller, A. Quesnel-Vallée, N.R. Caron, B. Vissandjée and G.P. Marchildon. 2018. Canada's Universal Health-Care System: Achieving Its Potential. The Lancet 391(10131): 1718-35. doi:10.1016/ s0140-6736(18)30181-8.

Ontario Ministry of Finance. 2012. Commission on the Reform of Ontario's Public Services. Retrieved December 10, 2018. <https://www.fin.gov.on.ca/en/reformcommission/chapters/report.pdf>.

Organisation for Economic Co-operation and Development (OECD). 2015, September 24. Healthcare Costs Unsustainable in Advanced Economies without Reform. Retrieved December 10, 2018. <http://www.oecd.org/ health/healthcarecostsunsustainableinadvancedeconomieswithoutreform.htm $>$.

Romanow, R.J. 2002, November. Building on Values: The Future of Health Care in Canada - Final Report. Commission on the Future of Health Care in Canada. Retrieved October 4, 2019. <http://publications.gc.ca/ collections/Collection/CP32-85-2002E.pdf>.

Schneider, E.C., D.O. Sarnak, D. Squires, A. Shah and M.M. Doty. 2017, July. Mirror, Mirror 2017: International Comparison Reflects Flaws and Opportunities for Better U.S. Health Care. The Commonwealth Fund. Retrieved December 10, 2018. <https://collections.nlm.nih.gov/master/borndig/101712671/Schneider_ mirror_mirror_2017.pdf>.

Schoen, C., R. Osborn, D. Squires, M.M. Doty, R. Pierson and S. Applebaum. 2010. How Health Insurance Design Affects Access to Care and Costs, by Income, in Eleven Countries. Health Affairs 29(12): $2323-$ 34. doi:10.1377/hlthaff.2010.0862.

Simpson, J. 2012. Chronic Condition: Why Canada's Health Care System Needs to be Dragged into the 21st Century. Penguin Random House Canada.

Smith, S., J.P. Newhouse and M.S. Freeland. 2009. Income, Insurance, and Technology: Why Does Health Spending Outpace Economic Growth? Health Affairs 28(5): 1276-84. doi:10.1377/hlthaff.28.5.1276.

Struthers, J. 2020, April 16. The Great Depression in Canada. The Canadian Encyclopedia. Retrieved January 1, 2021. <https://www.thecanadianencyclopedia.ca/en/article/great-depression>.

The Economist Intelligence Unit (EIU). 2018, January 24. Global Access to Healthcare. Retrieved January 2, 2021. <https://eiuperspectives.economist.com/healthcare/global-access-healthcare>.

World Health Organization (WHO). 2020, December 4. Key Country Indicators: Complete Data Set, Data from 2004 to 2017. Retrieved January 1, 2021. <http://apps.who.int/gho/data/node.cco.latest?lang=en>. 